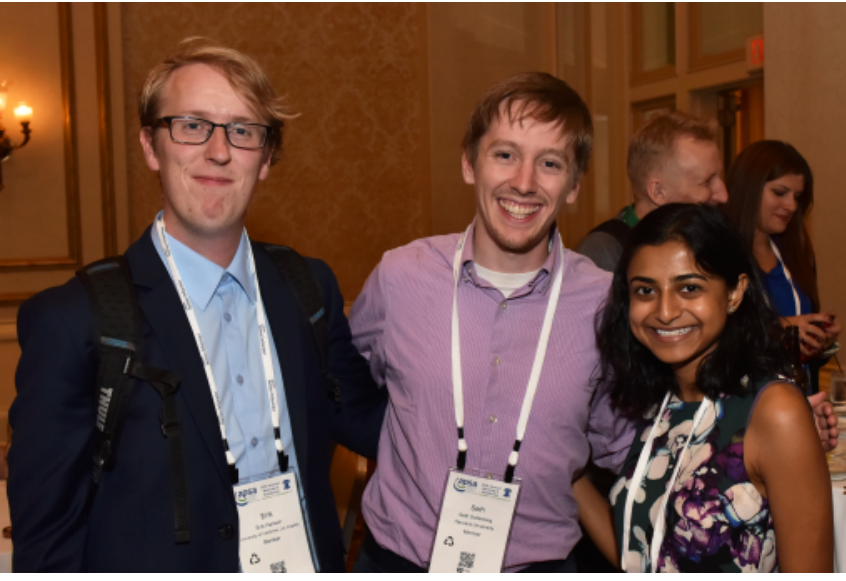

Attendees connect at a reception for graduate students. Even after the panels and meetings of the day, Annual Meeting events during the evening allow attendees to make lasting connections.

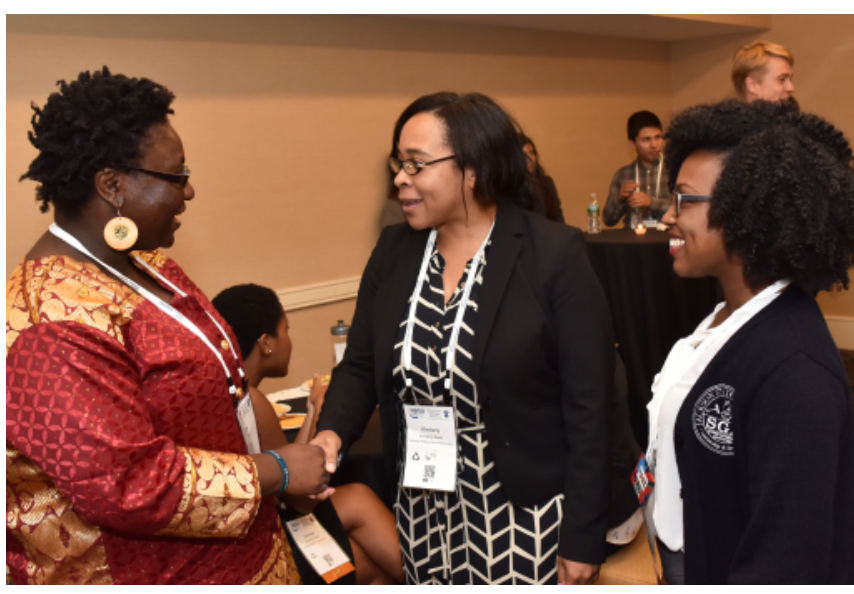

Kimberly Mealy, APSA, (C) talks with Remi Alapo (L) and Jasmine C. Jackson $(R)$ at the APSA Mentoring and Networking Reception, which was one of the many evening events to honor individual contributions to the discipline.

\title{
2016 APSA Ralph Bunche Scholars Present Posters
}

$\mathrm{B}$ enefitting from work completed at the 2016 Ralph Bunche Summer Institute, six RBSI scholars presented their research in a poster session at the Annual Meeting. These RBSI scholars presented on Saturday, September 3:

Jose S. Gomez, SUNY Binghamton University, "Contributions in Politics: Congressman, Constituent and Donor Ideological Relationships"

Jasmine Jackson, Jackson State University, “The Effect of Socioeconomic Factors on News Media Source Preference and African American Political Knowledge"

Heidi Obediente, University of Central Florida, "It's Not Women or Men: It's Balance"

Renzo Olivari, James Madison University, "Linked Fate and Latinos: Another American Invention?"

Danielle Russell, University of Connecticut, "Divided on Racial Lines: The Emergence of New Racism in Modern Public Opinion"

Jasmine Smith, Indiana University, "Racial Biases in Sentencing? A Comparative Analysis of Sentence Length between African American and White Women"

Priscilla Torres, Loyola Marymount University, "Beyond Victimization: Assessing Relief and Recovery Under UNSCR 1325" -

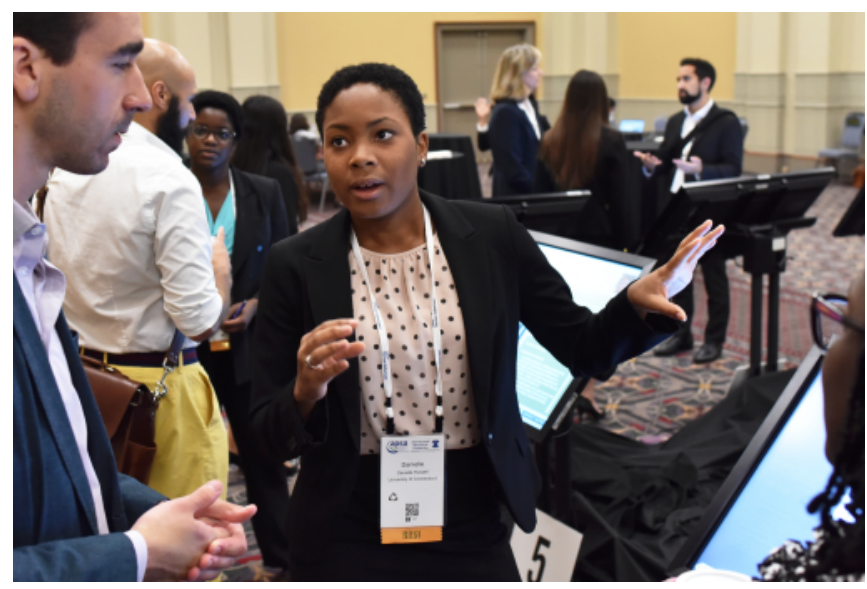

Danielle Russell, University of Connecticut, walks an attendee through her research.

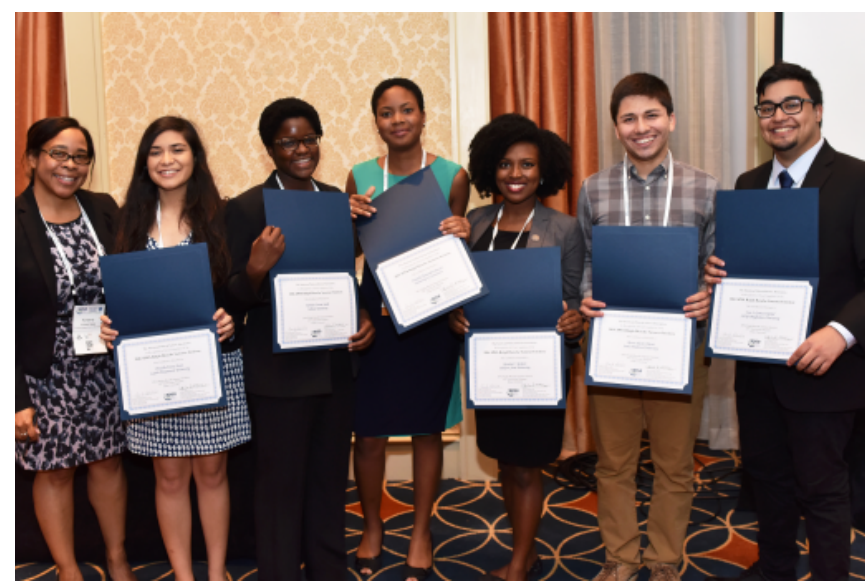

Kimberly Mealy, APSA, stands with the 2016 RBSI Scholars who attended this year's Annual Meeting. Left to right, they are Priscilla Torres, Jasmine Smith, Danielle Russell, Jasmine C. Jackson, Renzo Olivari, and Jose Gomez.

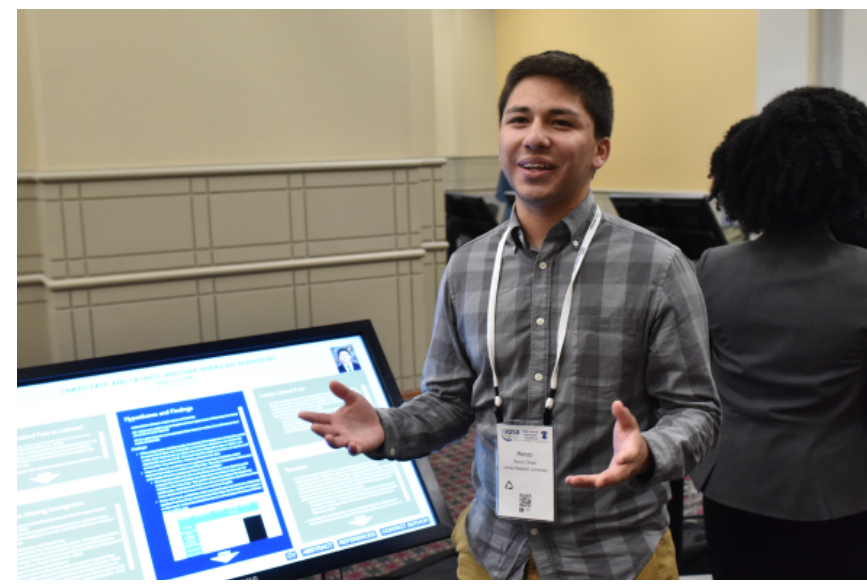

Renzo Olivari, James Madison University, discusses his iPoster. 